\title{
Laryngeal carcinoma in acromegalic patients: A rare case
}

\author{
*Gamze Akkuş, Mehtap Evran, Murat Sert, Tamer Tetiker \\ ${ }^{*}$ Cukurova University Medical Faculty, Department of Endocrinology, Adana, Turkey.
}

\section{Introduction:}

Acromegaly is a very rare disease with persistent GH secretion due to excessive release of liver IGF1. The risk of malignancy, particularly colon cancer, is increased in acromegalic patients. But no evidence is found in the literature associated increasing of laryngeal carcinoma in acromegalic patients. We aimed to present this case that laryngeal carcinoma should be considered in acromegaly by the clinicians.

\section{Case report:}

A 51 year-old male patient was diagnosed as acromegaly due to pituitary macroadenoma with the expansion of the suprasellar area localization in flood. He was operated the right pterional craniotomy at december 2003. Postoperatively he was given the 28x200 cGy doses of radiotherapy linear treatment because of residual mass lesion in screening control MRI (Figure 1). He was medicated somatostatin analogs without cured by radiotherapy. In 2011, he admitted to our clinic with hoarseness and left ventrikuler mass extending was found by direct laryngoscopy. Polypoid soft tissue mass with narrowing the air column of the left vocal cord was detected by simultaneously neck CT. Biopsy revealed squamous cell carcinoma. Total laryngectomy with left lateral neck dissection was performed. Malignancy was not detected in PET CT which made of restaging. Colonoscopy and endoscopy was performed and two polyps were found. As a result of pathology has been reported hyperplastic changes.

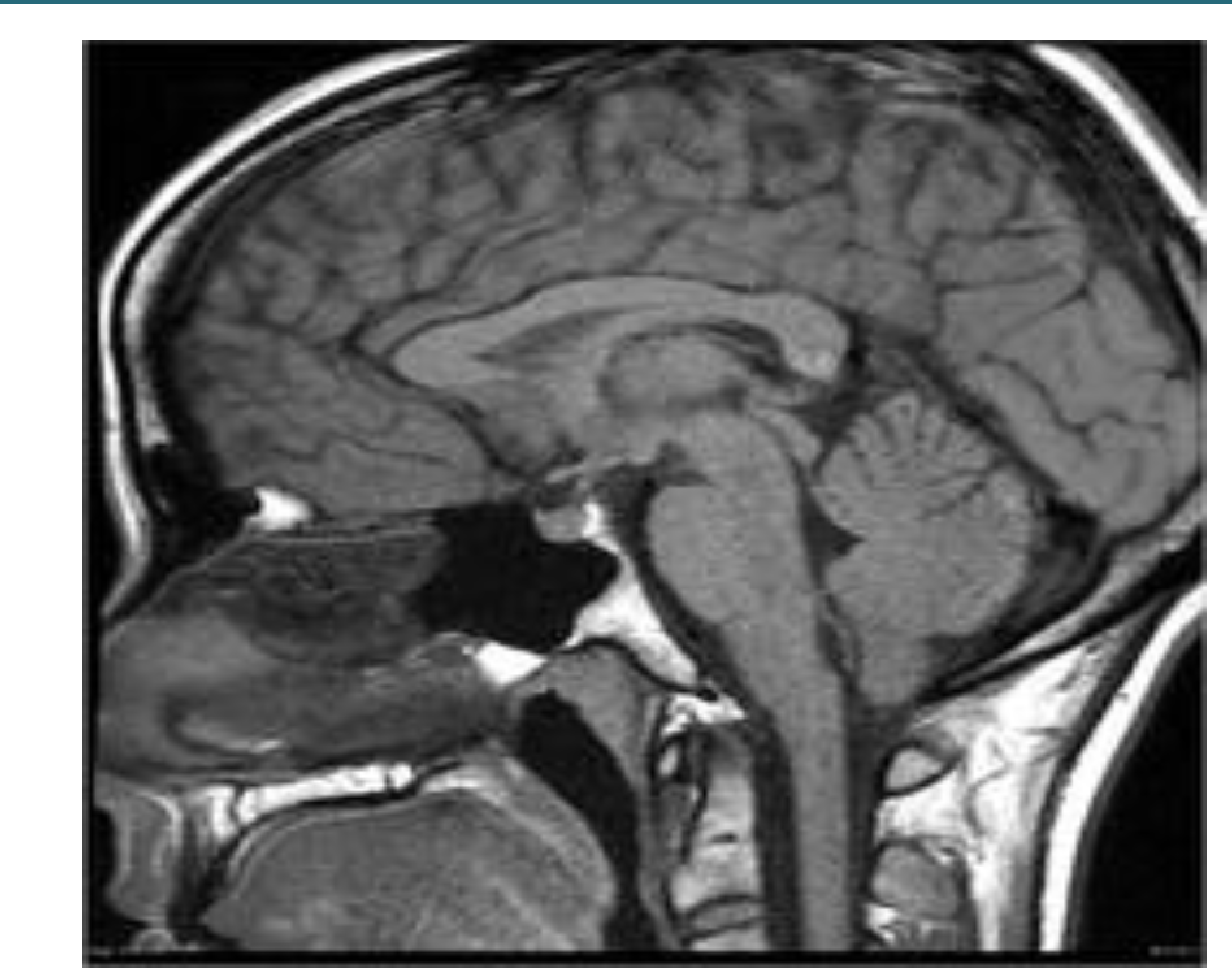

Figure 1. The residual mass lesion in screening of postoperative control MRI

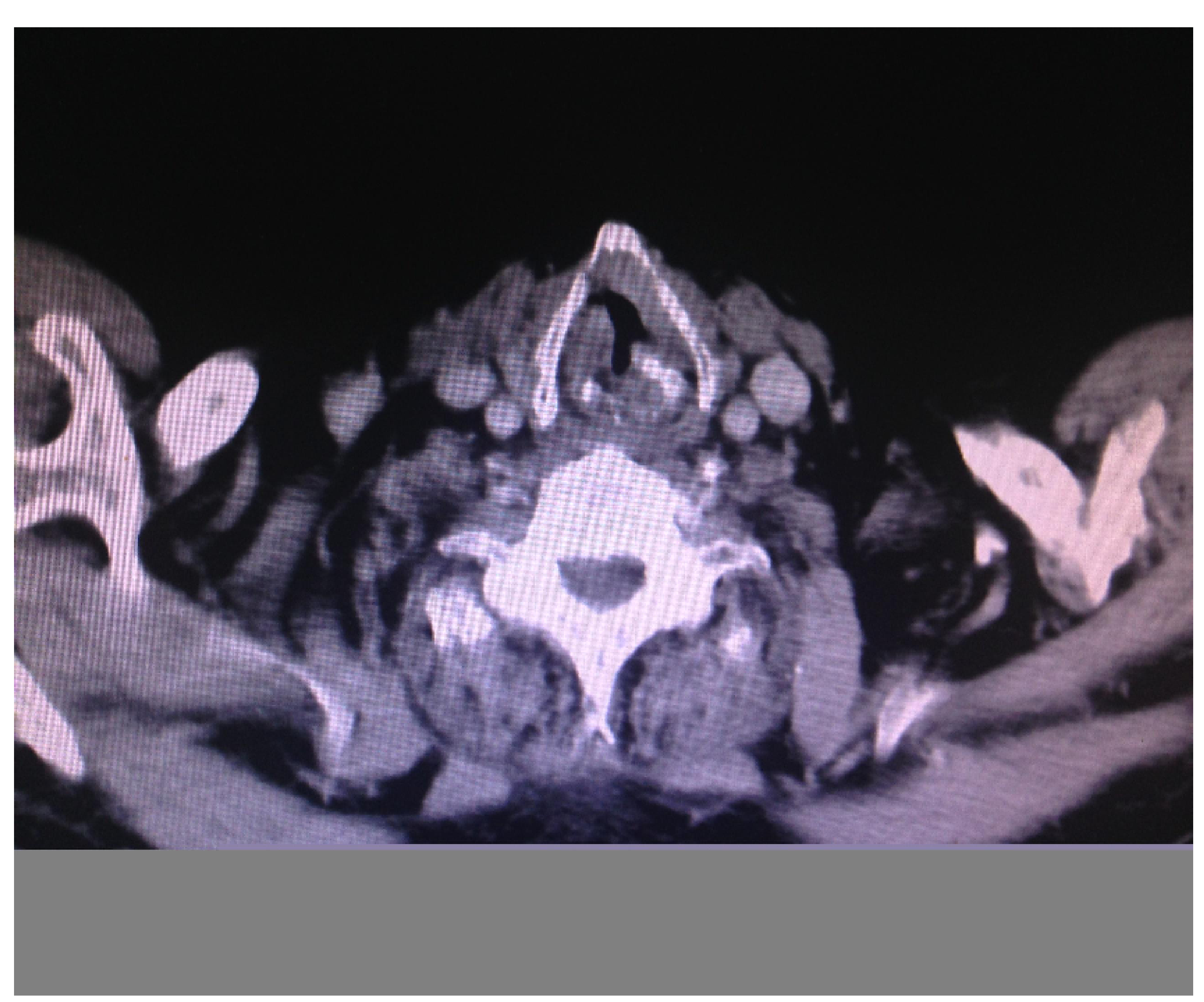

Figure 2. Polypoid soft tissue mass with narrowing the air column of the left vocal cord was showed by simultaneously neck CT.

\section{Conclusions:}

The elevated GH and IGF-I levels lead to a wide range of cardiovascular, respiratory diseases and malignancy also. A strong association between acromegaly and colon cancer and thyroid cancer has been highlighted. We could not find any data which acromegaly and in terms of laryngeal cancer association. However the laryngeal mucosa epitelium has been proven by the observational studies. We presented a case of a acromegaly patient who had a larynx carcinoma. Also clinicians should be aware that managing patients with acromegaly can ocur other malignancy. 